\title{
Long-term forecast of heavy metals content in wheat grain under changing climate conditions
}

\author{
Yuri B. Kirsta ${ }^{1}$, Alexander V. Puzanov ${ }^{1}$, Tamara A. Rozhdestvenskaya ${ }^{1}$ and \\ Maria P. Peleneva ${ }^{1}$ \\ ${ }^{1}$ Institute for Water and Environmental Problems of Siberian Branch of the Russian Academy of Sciences, Barnaul, Russia
}

\begin{abstract}
Using the system approach, we have developed a simulation model for the long-term forecast of the content of toxic chemical elements in grain crop yield. The study was carried out by the example of wheat cultivated in Altai Krai - one of the main grain-producing regions of Russia. Wheat crops were sampled in 10 municipal districts of Altai Krai, which characterize seven different edaphic-climatic zones. The average long-term values of mean monthly air temperature and monthly precipitation for each sampling area were identified using GIS and data of the Interactive Agricultural Ecological Atlas of Russia and Neighboring Countries. A total of 19 chemical elements were considered, i.e. $\mathrm{Pb}$, As, $\mathrm{Cd}, \mathrm{Hg}, \mathrm{Na}, \mathrm{Mn}, \mathrm{Zn}, \mathrm{Cu}, \mathrm{Fe}, \mathrm{Co}$, etc. It is shown that content of $\mathrm{Pb}, \mathrm{Na}, \mathrm{Mn}$ and $\mathrm{Cu}$ in wheat depend on climatic characteristics of the cultivation area. Regression dependences of element content on the average long-term air temperature and precipitation were established. Based on normalization and spatial generalization of air temperature and precipitation providing the uniform dynamics of their relative monthly values (in percent) throughout the study area, a forecast of their changes was made for 2030. A procedure for grain sampling, GIS technologies for processing meteorological and cartographic data, methods for predicting regional climate changes and establishment of quantitative relationships of chemical elements content in grain with climatic characteristics - all together make up the integral predictive simulation model for toxic substance content in grain crop yield. The model was used for estimation of $\mathrm{Pb}, \mathrm{Na}, \mathrm{Mn}, \mathrm{Cu}$ changes in wheat by 2030 . The lead $(\mathrm{Pb})$ content in wheat crop delivered to elevators from certain municipal districts will exceed the maximum allowable concentration for breadgrain after 2030. Unlike $\mathrm{Pb}, \mathrm{Na}, \mathrm{Mn}, \mathrm{Cu}$, the content of other metals in wheat grain weakly correlate with long-term changes in air temperature and precipitation; therefore, it can hardly change significantly.
\end{abstract}

\section{Keywords}

Cereals, wheat, heavy metals, forecast, climate change, Altai.

\section{Introduction}

Our research is devoted to the development of a methodology for simulation modeling and forecasting the heavy metals content in wheat grain by 2030 with minimum data of observations. We take as an example the Altai Krai that is one of the largest grain-producing regions of the Russian Federation. The heavy metals content depends on the climate and the hard-to-consider local conditions of crop cultivation area, including local soil characteristics, rotation crops, chemicals used and many other factors. Remaining within the framework of the system approach, we will use statistical methods of data processing that are traditionally used in forecasting poorly

SDM-2021: All-Russian conference, August 24-27, 2021, Novosibirsk, Russia

$\bigoplus$ kirsta@iwep.ru (Y. B. Kirsta)

(c) (1) $\odot 2021$ Copyright for this paper by its authors. Use permitted under Creative Commons License Attribution 4.0 International (CC BY 4.0).

CEUR Workshop Proceedings (CEUR-WS.org) 
studied complex processes. Wheat cultivation technologies and soil characteristics affecting the quality of grain remain stable over long periods, in contrast to modern climate changes. It is the influence of the latter that we will analyze.

Currently, a large number of empirical-statistical and deterministic methods of long-term meteorological forecasts, as well as their various combinations, are proposed [1, 2, 3, 4]. The first ones are based on the statistical regularities of atmospheric processes and require the maximum volume and homogeneity of the studied series of meteorological data. The latter are founded on the physical laws of atmospheric or atmospheric-oceanic processes and describe them by complex equations as, for example, in the mesoscale WRF model $[5,6]$.

\section{Basic data}

When developing universal predictive models, characterizing long-term changes in chemical elements content in cereals, it is necessary to move from specific units of substance measurement to dimensionless characteristics [7, 8]. We normalized the observational data of each element content to its average for the Altai Krai (for all sampling municipal districts characterizing seven edaphic-climatic zones) and expressed them as a percentage of this average (Table 1).

To assess the climate situation in the Altai Krai and adjacent territories, we used 11 reference weather stations with observations 1951-2020 [10,11]. According to the developed method

Table 1

Chemical elements content in wheat grain in 2018-2019, normalized to the average values over the territory, \%.

\begin{tabular}{|c|c|c|c|c|c|c|c|c|c|c|c|c|}
\hline \multirow{2}{*}{ 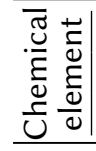 } & \multicolumn{10}{|c|}{ Sampling district number } & \multirow{2}{*}{$\begin{array}{c}\text { Average }^{1}, \\
\mathrm{mg} / \mathrm{kg}\end{array}$} & \multirow{2}{*}{$\begin{array}{c}\text { Allowable } \\
\text { limit }^{2}, \\
\text { mg/kg }\end{array}$} \\
\hline & 1 & 2 & 3 & 4 & 5 & 6 & 7 & 8 & 9 & 10 & & \\
\hline $\mathrm{Pb}$ & 34.5 & 37.53 & 56.3 & 133.17 & 133.17 & 169.49 & 127.12 & 133.17 & 96.85 & 78.69 & 0.1652 & 0.5 \\
\hline $\mathrm{Cd}$ & 45.05 & 103.6 & 108.11 & 45.05 & 148.65 & 144.14 & 45.05 & 108.11 & 117.12 & 135.14 & 0.0222 & 0.1 \\
\hline $\mathrm{Ca}$ & 99.52 & 102.21 & 99.52 & 107.58 & 10.22 & 115.65 & 110.27 & 102.21 & 134.48 & 118.34 & 3718 & - \\
\hline $\mathrm{K}$ & 109 & 85.31 & 87.68 & 90.05 & 99.53 & 113.74 & 97.16 & 130.33 & 99.53 & 87.68 & 4.22 & - \\
\hline$M g$ & 107.96 & 106.13 & 96.07 & 100.18 & 110.7 & 150.96 & 90.58 & 135.41 & 13.08 & 88.75 & 1093 & - \\
\hline $\mathrm{Na}$ & 76.82 & 69.14 & 57.62 & 69.14 & 172.86 & 179.26 & 96.03 & 140.85 & 69.14 & 69.14 & 78.1 & - \\
\hline $\mathrm{P}$ & 98.67 & 90.67 & 88 & 88 & 88 & 114.67 & 117.33 & 117.33 & 106.67 & 90.67 & 3750 & - \\
\hline$M n$ & 91.06 & 106.24 & 80.94 & 97.81 & 106.24 & 111.3 & 97.81 & 119.73 & 96.12 & 92.75 & 59.3 & - \\
\hline $\mathrm{Zn}$ & 125.62 & 152.71 & 76.35 & 113.3 & 105.91 & 105.91 & 91.13 & 76.35 & 88.67 & 64.04 & 40.6 & - \\
\hline $\mathrm{Cu}$ & 106.64 & 117.13 & 78.67 & 111.89 & 110.14 & 106.64 & 104.9 & 115.38 & 82.17 & 66.43 & 5.72 & - \\
\hline $\mathrm{Fe}$ & 116.07 & 133.93 & 108.63 & 84.82 & 111.61 & 114.58 & 92.26 & 78.87 & 83.33 & 75.89 & 67.2 & - \\
\hline $\mathrm{Co}$ & 9.171 & 9.171 & 9.171 & 148.62 & 89.91 & 104.59 & 177.98 & 201.83 & 161.47 & 88.07 & 0.0545 & - \\
\hline $\mathrm{Al}$ & 56.95 & 125.28 & 63.78 & 116.17 & 100.23 & 125.28 & 184.51 & 50.11 & 111.62 & 66.06 & 43.9 & - \\
\hline $\mathrm{Ba}$ & 150.63 & 87.87 & 125.52 & 83.68 & 79.5 & 125.52 & 58.58 & 125.52 & 71.13 & 92.05 & 2.39 & - \\
\hline Mo & 40.12 & 19.55 & 56.58 & 95.68 & 22.63 & 59.67 & 339.51 & 87.45 & 226.34 & 52.47 & 0.972 & - \\
\hline $\mathrm{Ni}$ & 35.61 & 83.09 & 68.25 & 127.6 & 130.56 & 94.96 & 97.92 & 225.52 & 80.12 & 56.38 & 0.337 & - \\
\hline
\end{tabular}

${ }^{1}$ We normalized the value of $0.005 \mathrm{mg} / \mathrm{kg}$ as half of the element detection limit of $0.01 \mathrm{mg} / \mathrm{kg}$.

${ }^{2}$ Allowable level in bread-grain, $\mathrm{mg} / \mathrm{kg}$ [9]. 
of normalization and spatial generalization of meteorological data $[7,12,13,14]$, the observed values of air temperature and precipitation for each month in each year were recalculated as a percentage relative to their "in situ" average long-term values for January and July. Such normalized values allow a uniform description of long-term changes in temperature and precipitation over plain and mountainous areas. To switch back to the generally accepted units of factor measurements $\left({ }^{\circ} \mathrm{C}, \mathrm{mm}\right)$, it is enough to know their average long-term January and July values in the characterized location.

\section{Forecast of changes in air temperature and precipitation by 2030}

The system analysis of climate dynamics for the grain-producing zone of Russia showed that this dynamics obeys an age-long climatic cycle consisting of three 33-year phases [11, 15, 16]. These phases cover 1918-1950, 1951-1983, 1984-2016, and each of them is characterized by certain statistical regularities of long-term changes in normalized air temperature and precipitation. To predict these factors by 2030, we used the meteorological patterns of the third phase as the closest to the forecast period. We normalized and spatially generalized (averaged over 11 reference weather stations) the monthly values of these factors for 1984-2020. Then, using the obtained data, we calculated the long-term linear trends of factors for each month of the year. Extrapolating the found trends for 10 years ahead, we obtained normalized monthly values of air temperature and precipitation expected by 2030.

The forecast shows that by 2030 the average monthly air temperature in January will decrease $(\sim 20 \%)$, in March and April will increase ( $>20 \%$ ), and will remain approximately the same in the other months. The predicted changes in monthly precipitation are multidirectional by months of the year. Note that the forecast of normalized climatic characteristics is uniform throughout the Altai Krai, regardless of the orographic and climatic heterogeneity of its territory.

\section{Relationship between heavy metals content in wheat grain and climatic conditions}

The short observation period 2018-2019 for chemical elements content in wheat grain (Table 1) does not allow us to find its dependence on climatic factors directly. Because of this, we compared this content with the average long-term values of mean monthly air temperature and monthly precipitation corresponding to the sampling municipal districts. Each of 10 sampling districts (Table 1) has its own average long-term values of climatic factors. As a result, it becomes possible to determine the relationship between the substance content in grain and these factors.

To estimate the average long-term monthly values of air temperature and precipitation for each sampling district, we used the Interactive Agricultural Ecological Atlas of Russia and Neighboring Countries [17]. We calculated these values by means of the GIS platform ArcGIS Desktop 10.0. Then we normalized and spatially generalized them over the territory of the Altai Krai. The data obtained made it possible to link the substance content in the grain with climatic factors. 
To describe most adequately the substance content in wheat grain as a function of temperature and precipitation, we first determined the influence of their monthly values separately. For this purpose, the correlation between the normalized content of each chemical element and the average long-term normalized values of mean monthly air temperature and monthly precipitation was found. Then we identified the months that gave the highest correlation coefficients for each meteorological factor. Precipitation showed a more significant impact if compared to air temperature. It turned out that the chemical elements content in grain significantly depends on the meteorological factors of winter period. Combining the months found for each meteorological factor, we calculated the final correlation coefficients between the chemical elements content and the factors (Table 2). In Table 2, the largest correlation coefficients are shown in bold.

Choosing the chemical elements $\mathrm{Pb}, \mathrm{Na}, \mathrm{Mn}, \mathrm{Cu}$, which are most dependent on meteorological factors (Table 2), we determined the relationship of their content in wheat grain with the average long-term normalized values of air temperature and precipitation, that is, with climatic conditions in the Altai Krai. For each found linear relationship, we also calculated the reliability of approximation $R^{2}$ (coefficient of determination). The linear dependences $\mathrm{Pb}\left(\left[P_{1}+P_{2}+\right.\right.$ $\left.\left.\cdots+P_{12}\right] / 12\right), \mathrm{Na}\left(\left[P_{1}+P_{2}+\cdots+P_{12}\right] / 12\right), \mathrm{Mn}\left(\left[P_{7}+P_{8}\right] / 2\right), \mathrm{Cu}\left(\left[P_{5}+P_{6}+P_{7}\right] / 3\right)$, $\mathrm{Pb}\left(\left[T_{5}+T_{6}+T_{7}+T_{8}\right] / 4\right), \mathrm{Na}\left(\left[T_{5}+T_{6}+T_{7}+T_{8}\right] / 4\right), \mathrm{Cu}\left(\left[T_{12}+T_{1}+T_{2}+T_{3}\right] / 4\right)$ showed the sufficiently high values of $R^{2}: 0.59,0.66,0.52,0.51,0.68,0.61,0.63$, correspondingly.

Different soil characteristics and other agricultural factors affect the scatter of data relative to the regression lines and reduce the coefficient of determination $R^{2}$. At the same time, the

\section{Table 2}

Correlation coefficients between the normalized chemical elements content in wheat grain (Table 1) and the average long-term normalized monthly values of air temperature $\left(T_{i}, i=1, \ldots, 12\right)$ and precipitation $\left(P_{i}, i=1, \ldots, 12\right)$.

\begin{tabular}{|c|c|c|c|c|c|}
\hline $\begin{array}{l}\text { Chemical } \\
\text { element }\end{array}$ & $\frac{T_{5}+T_{6}+T_{7}+T_{8}}{4}$ & $\frac{T_{12}+T_{1}+T_{2}+T_{3}}{4}$ & $\frac{P_{1}+P_{2}+\cdots+P_{12}}{12}$ & $\frac{P_{5}+P_{6}+P_{7}}{3}$ & $\frac{P_{7}+P_{8}}{2}$ \\
\hline $\mathrm{Pb}$ & 0.8236 & -0.3222 & -0.7682 & -0.6535 & -0.7442 \\
\hline $\mathrm{Cd}$ & 0.1776 & 0.2511 & -0.1450 & -0.0677 & -0.1636 \\
\hline $\mathrm{Ca}$ & -0.2649 & 0.5313 & 0.4699 & 0.4902 & 0.3927 \\
\hline $\mathrm{K}$ & 0.4964 & -0.2482 & -0.4559 & -0.4663 & -0.5913 \\
\hline $\mathrm{Mg}$ & 0.6432 & -0.6754 & -0.6700 & -0.6730 & -0.6142 \\
\hline $\mathrm{Na}$ & 0.7812 & -0.4536 & -0.8099 & -0.7361 & -0.8151 \\
\hline $\mathrm{P}$ & 0.4518 & 0.0611 & -0.2239 & -0.1941 & -0.3643 \\
\hline$M n$ & 0.5612 & -0.3372 & -0.5647 & -0.5679 & -0.7191 \\
\hline $\mathrm{Zn}$ & -0.0930 & -0.4645 & -0.1322 & -0.2132 & -0.1756 \\
\hline $\mathrm{Cu}$ & 0.4808 & -0.7967 & -0.6196 & -0.7118 & -0.7127 \\
\hline $\mathrm{Fe}$ & 0.0464 & -0.4316 & -0.1726 & -0.2483 & -0.1673 \\
\hline Co & 0.4089 & 0.0613 & -0.2759 & -0.2188 & -0.3647 \\
\hline $\mathrm{Al}$ & 0.2769 & -0.1029 & -0.1911 & -0.1380 & -0.1769 \\
\hline $\mathrm{Ba}$ & 0.0848 & -0.2507 & -0.1316 & -0.1829 & -0.1309 \\
\hline Mo & 0.0560 & 0.2901 & 0.1603 & 0.1914 & 0.1086 \\
\hline $\mathrm{Ni}$ & 0.6028 & -0.4197 & -0.5612 & -0.6224 & -0.6971 \\
\hline
\end{tabular}


nature of soils in agroecosystems cannot change significantly over a decade. Considering this and "in situ" normalization of meteorological factors, we can use the found dependences to predict changes in the chemical elements content in wheat grain by 2030. "In situ" soil features therewith have little effect on the reliability of such forecast.

\section{Forecast of heavy metals content in wheat grain for 2030}

The following simulation linear equation is used to predict the chemical elements content in grain crop yield:

$$
F C=C C+k \times(M V 30-M V),
$$

where $F C$ is the predicted content of chemical element $(\mathrm{Pb}, \mathrm{Na}, \mathrm{Mn}, \mathrm{Cu})$ in wheat grain by 2030 ; $C C$ is the current value of the content (2018-2019); $k$ is the slope coefficient of linear regression for the element content depending on climatic conditions; $M V$ is "in situ" average long-term monthly values of precipitation or air temperature: $\left[P_{1}+P_{2}+\cdots+P_{12}\right] / 12,\left[P_{5}+P_{6}+P_{7}\right] / 3$, $\left[P_{7}+P_{8}\right] / 2,\left[T_{5}+T_{6}+T_{7}+T_{8}\right] / 4,\left[T_{12}+T_{1}+T_{2}+T_{3}\right] / 4 ; M V 30-$ the analogous values of precipitation or air temperature that are predicted for 2030 . The forecast equation characterizes the increase or decrease in the chemical elements content in grain, depending on the change $(M V 30-M V)$ of climatic characteristic.

The 2030 forecast on the $\mathrm{Pb}, \mathrm{Na}, \mathrm{Mn}, \mathrm{Cu}$ content in wheat grain showed that the influence of air temperature during growth season is noticeably stronger than of precipitation. The influence of winter air temperature $\left[T_{12}+T_{1}+T_{2}+T_{3}\right] / 4$, which determines the degree of freezing of soils, the intensity of their thawing in spring and, hence, the development of cereal seedlings, is also significant (Figure 1).

The forecast (Figure 1) allows us to estimate critical changes in the chemical elements content in wheat crop yields by 2030. Consider the strong dependence of $\mathrm{Pb}$ on air temperature $\left[T_{5}+T_{6}+T_{7}+T_{8}\right] / 4$ during the growth season May-August. This dependence leads to a significant increase in the $\mathrm{Pb}$ content up to $200-250 \%$ in $4^{\text {th }}, 5^{\text {th }}, 6^{\text {th }}, 7^{\text {th }}$ and $8^{\text {th }}$ districts of the Altai Krai. These are Romanovsky, Rodinsky, Klyuchevskoy, Aleisky (steppe) and Yegoryevsky districts [10]. Converting percentages into units of substance measurement $\mathrm{mg} / \mathrm{kg}$ (see Table 1), we find that, for example, in Klyuchevskoy district (No. 6) the Pb content in grain by 2030 will reach the following value:

(Average Pb content $) \times 250 / 100=0.1652 \times 2.5=0.41 \mathrm{mg} / \mathrm{kg}$.

The resulting value is critically close to the allowable level of $\mathrm{Pb}$ in food wheat, which is $0.5 \mathrm{mg} / \mathrm{kg}$ (Table 1). After 2030, the $\mathrm{Pb}$ content in some grain shipments delivered to grain elevators will exceed this level due to the natural statistical variation of this characteristic. The content of other chemical elements in wheat grain (Table 1) will change insignificantly and not prevent its use for food purposes.

The presented forecast model of the chemical elements content in grain yield is based on the system analysis and mathematical simulation modeling of climatic and agroecosystem processes. It includes predicted trends in air temperature and precipitation, linear regressions for chemical elements, the content of which in cereals is sensitive to changes in climatic conditions. The 

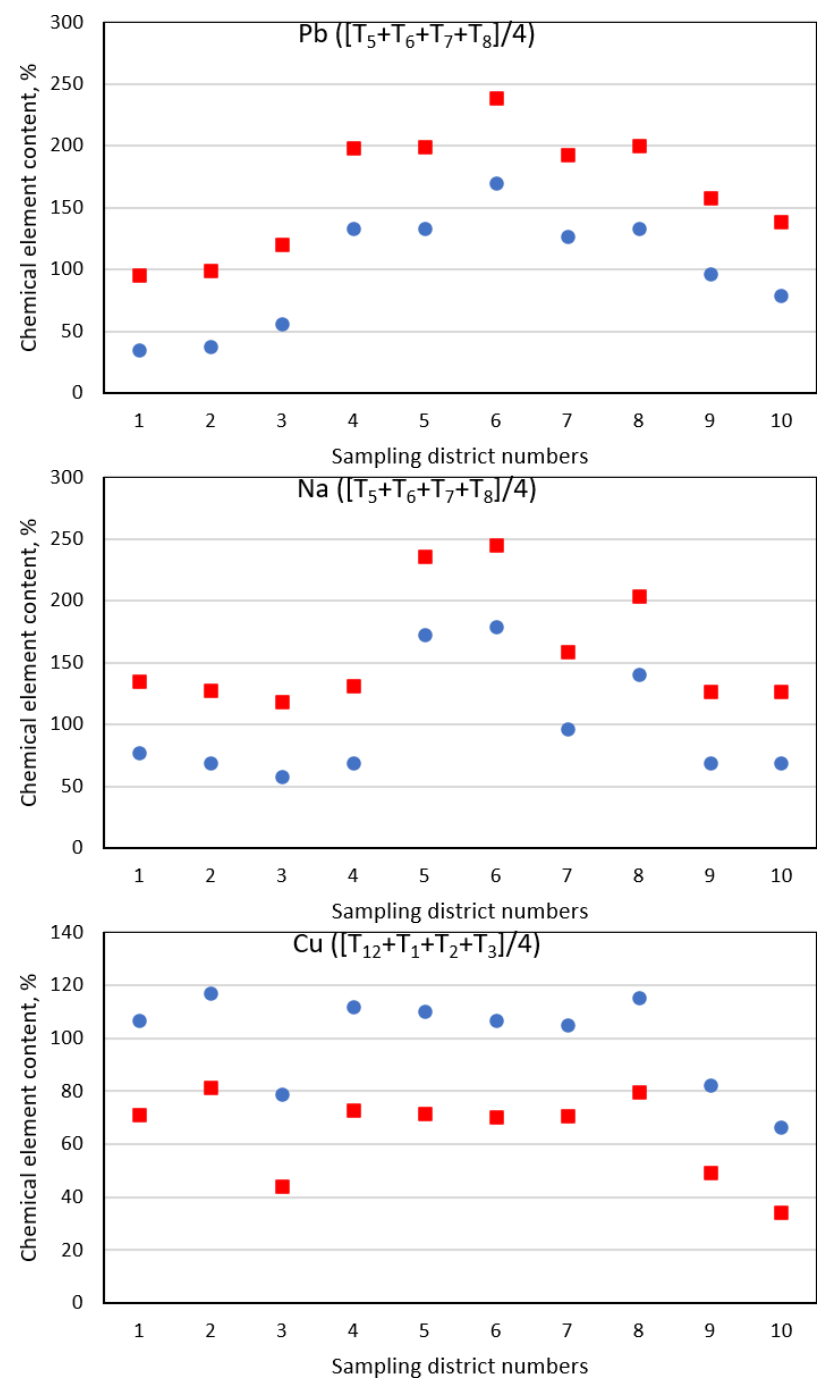

Figure 1: The content of lead $\mathrm{Pb}$, sodium $\mathrm{Na}$, and copper $\mathrm{Cu}$ in wheat crop yields in 10 sampling municipal districts of the Altai Krai as a percentage of the average values for the territory (Table 1). $(\bullet)$ - measured in 2018-2019, (ם) - predicted for 2030, $T_{i}$ - average long-term temperature in the month $i, i=1, \ldots, 12$.

method for constructing climatic trends is supported by successful long-term forecasts of air temperature, precipitation and wheat crop yields in the USA, Russia, the Siberian Federal District and the Altai Krai $[10,12,15,18]$. The adequacy of linear regression equations for chemical elements content is confirmed by significant values of their determination coefficient $R^{2}$. Thus, the developed model provides an adequate forecast of the chemical elements content in wheat grain for 2030. It is well established that the content of lead $(\mathrm{Pb})$ in some wheat shipments delivered to grain elevators after 2030 will exceed the maximum allowable concentration for bread-grain. 


\section{Acknowledgments}

The work was carried out within the framework of the Research Program of the Institute for Water and Environmental Problems SB RAS (Project 1021032424138-9) with the financial support of the Russian Foundation for Basic Research (grant No. 18-45-220019-r_a).

\section{References}

[1] Parton K.A., Crean J. Review of the literature on valuing seasonal climate forecasts in Australian agriculture. Report for the Project Improved Use of Seasonal Forecasting to Increase Farmer Profitability. Australia, Orange: NSW DPI, 2016.

[2] Siegert S., Bellprat O., Menegoz M. et al. Detecting improvements in forecast correlation skill: Statistical testing and power analysis // Monthly Weather Review. 2017. Vol. 145(2). P. 437-450.

[3] NCEP Generated Products. In: National Centers for Environmental prediction. 2020. Available at: https://www.nco.ncep.noaa.gov/pmb/products (accessed March 10, 2020).

[4] Kirsta Y.B., Lovtskaya O.V. Annual range of temperature and precipitation forecast for Altai-Sayan mountain country // Environmental Dynamics and Global Climate Change. 2020. Vol. 11. No. 1. DOI:10.17816/edgcc34020.

[5] Skamarock W.C., Klemp J.B., Dudhia J. et al. Description of the Advanced Research WRF. Version 3. NCAR Technical Note NCAR/TN-475+STR. 2008. 520 p. DOI:10.5065/D68S4MVH.

[6] Ignatov R.Yu., Zaichenko M.Yu. et al. Comparison of regional atmospheric model forecasts under different initial and boundary conditions // Russian Meteorology and Hydrology. 2019. Vol. 44: P. 378-383.

[7] Kirsta Y.B., Lovtskaya O.V. Spatial year-ahead forecast of air temperature and precipitation in large mountain areas // SN Appl. Sci. 2020. Vol. 2. No. 1044. DOI:10.1007/s42452-0202861-6.

[8] Kirsta Y.B., Puzanov A.V. System-analytical modelling: 1. Development of regional models for mountain river runoff // Eurasian Journal of Mathematical and Computer Applications. 2020. Vol. 8. Is. 2. P. 69-85. DOI:10.32523/2306-6172-2020-8-2-69-85.

[9] Technical Regulation of the Customs Union "On Safety of Grain" (TR TS 015/2011) adopted by the CCU Decision No. 874 on 9 December 2011, and came into force on 1 July 2013.

[10] Kirsta Y.B., Kurepina N.Y., Lovtskaya O.V. The forecast of climate and agroclimatic potential in Altai Krai up to 2020 // Bulletin of Altai State Agricultural University. 2013. No. 1. P. 27-32.

[11] Kirsta Y.B., Lovtskaya O.V., Puzanov A.V. The forecast of climate changes in Altai-Sayan mountain country till 2030 // CEUR Workshop Proceedings. 2019. Vol. 2534 P. 114-117. http://ceur-ws.org/Vol-2534/19_short_paper.pdf

[12] Kirsta Yu.B. System-analytical modelling - Part II: Wheat biotime run and yield formation. Agroclimatic potential, Le Chatelier principle, changes in agroclimatic potential and climate in Russia and the U.S. // Ecol. Modelling. 2006. Vol. 191. P. 331-345. DOI:10.1016/j.ecolmodel.2005.05.027.

[13] Kirsta Y.B., Lovtskaya O.V. The forecast of climatic changes in grain-producing areas of 
Siberia and Russia // World Sci. Cult. Educ. (Mir Nauki, Kul'tury, Obrazovaniya). 2009. No. 7. P. 9-13. Available at: http://amnko.ru/index.php/english/journals (accessed June 1, 2021).

[14] Kirsta Y.B. Spatial generalization of climatic characteristics in mountain areas // World Sci. Cult. Educ. (Mir Nauki, Kul'tury, Obrazovaniya). 2011. No. 3. P. 330-337. Available at: http://amnko.ru/index.php/english/journals (accessed June 1, 2021).

[15] Kirsta Y.B., Kirsta B.Y. The information-physical principle of evolutionary systems formation. System-analytical modelling of ecosystems. 2nd ed. Barnaul: Altai State University Publishing House, 2014. 283 p. (In Russ.)

[16] Kirsta Y.B. System analysis and forecast of climate in the grain-producing zone of Russia until 2020 // Proceedings of the All-Russian Conference Dedicated to the 90th Anniversary of Academician M.I. Budyko, 10-11 June 2010. St. Petersburg: BBM, 2010. P. 34-36.

[17] Afonin A.N., Greene S.L., Dzyubenko N.I., Frolov A.N. (eds.). Interactive agricultural ecological atlas of Russia and neighboring countries. Economic Plants and Their Diseases, Pests and Weeds [Online]. 2008. Available at: http://www.agroatlas.ru (accessed June 1, 2021).

[18] Kirsta Y.B. The forecast of both climate and agroclimatic potential in Siberian Federal Okrug till 2020 // Regional Environmental Issues. 2011. No. 3. P. 22-30. 